\title{
Current Research in Hydrology and Water Resources
}

Brief Report

Nikolaevich PG and Munavvarovich AH Curr Res Hydrol Res: CRHR-119.

\section{The Variability of the Water Runoff of the Rivers of the Aral Sea Basin in the Context of Global Climate Change}

\author{
Petrov Georgy Nikolaevich*, Akhmedov Hakim Munavvarovich
}

Department of Electrical Equipment and Energy Conservation, Orel State University, Russia

*Corresponding author: Petrov Georgy Nikolaevich, Department of Electrical Equipment and Energy Conservation, Orel State University, Orel, st. Priborostroitelnaya, 59, 84, Russia. Tel: +7-9102027982; Email: geomar@bk.ru

Citation: Nikolaevich PG, Munavvarovich AH (2019) The Variability of the Water Runoff of the Rivers of the Aral Sea Basin in the Context of Global Climate Change. Curr Res Hydrol Res: CRHR-119. DOI: 10.29011/CRHR-119. 100019

Received Date: 08 January, 2019; Accepted Date: 21 January, 2019; Published Date: 28 January, 2019

\section{Abstract}

The article analyzes the general variability of water runoff in the rivers of the Aral Sea basin and suggests a method for its reliable assessment in terms of the impact on water resources of global climate change.

Keywords: Cyclic Variability; Forecast of Water Runoff; Linear Trend; Water Basin; Water Runoff

\section{Introduction}

The Aral Sea basin in Central Asia includes two main rivers basins-the Amudarya and the Syrdarya, located on the territory of five states- Kazakhstan, Kyrgyzstan, Tajikistan, Turkmenistan, and Uzbekistan. Both rivers, the Amudarya and the Syrdarya, are formed in the mountainous regions of Kyrgyzstan and Tajikistan, then flow through the arid territories of the lower countries and flow into the Aral Sea.

Since ancient times, the water resources of all the rivers of the Aral Sea basin have been actively used for irrigated agriculture, especially intensively in the second half of the last century. As a result, a sharp shortage of water appeared in the region, which led to the death of the Aral Sea, the consequences of which are still being felt. Under these conditions, the issue of a reliable forecast of water flow becomes extremely important, especially in the context of global warming [1]. The water resources of rivers, for all their merits, are very variable in time. For example, for Vakhsh and Naryn, the largest rivers forming the Syrdarya and Amudarya basins and intensively used for energy and for irrigation, the annual flow for the entire observation period changed, respectively, 1.93.8 times, the average monthly water flow in the river-15 20 times, and flood flow, compared with the minimum flow - 50 or more times [2].

This variability over more than 300 years of intensive use of water resources in world practice has been well studied and effective methods for calculating, building and operating river hydraulic structures, including unique in scale, ensuring their reliability and safety, have been developed. But at the same time, all these calculations are based on constant (changing only due to new observations and increasing the length of the time series), time-independent statistical parameters. This method of calculation was developed in the first half of the 20th century on the basis of measurements of the runoff of the late 19th and early 20th centuries.

Therefore, the current calculation methods do not take into account the global climate change processes that have begun after this, although many experts predict that these changes can be very significant. In order to confirm or refute this, a special analysis is needed not only of the general parameters of statistical variability, but of variability over time. Taking into account that all changes in other already measured climate change parameters (temperature, $\mathrm{CO}_{2}$ content, etc.) occur very slowly, for a water runoff the linear trend would be most suitable for this purpose.

Unfortunately, the mechanical use of linear correlation for these methods leads to insufficiently adequate results. For example, the standard linear trends of the water runoff of the Vakhsh and Naryn rivers differ sharply from each other, both in trend and magnitude (Figure 1). This is impossible to find any logical explanation, since they are formed in almost the same climatic and geological conditions. It is also impossible to explain the fact that the water flow r. Naryn according to (Figure 1) increases with an intensity of $2.4 \%$ over 10 years, but at the same time there is neither a noticeable increase in electricity generation at the cascade of the Naryn Hydroelectric Power Stations, nor a water flow increase in the Syrdarya river basin, into which the Naryn river flows. 


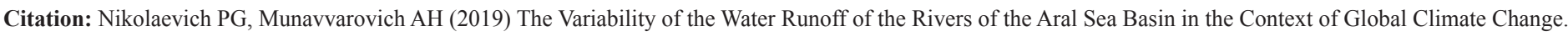
Curr Res Hydrol Res: CRHR-119. DOI: 10.29011/CRHR-119. 100019

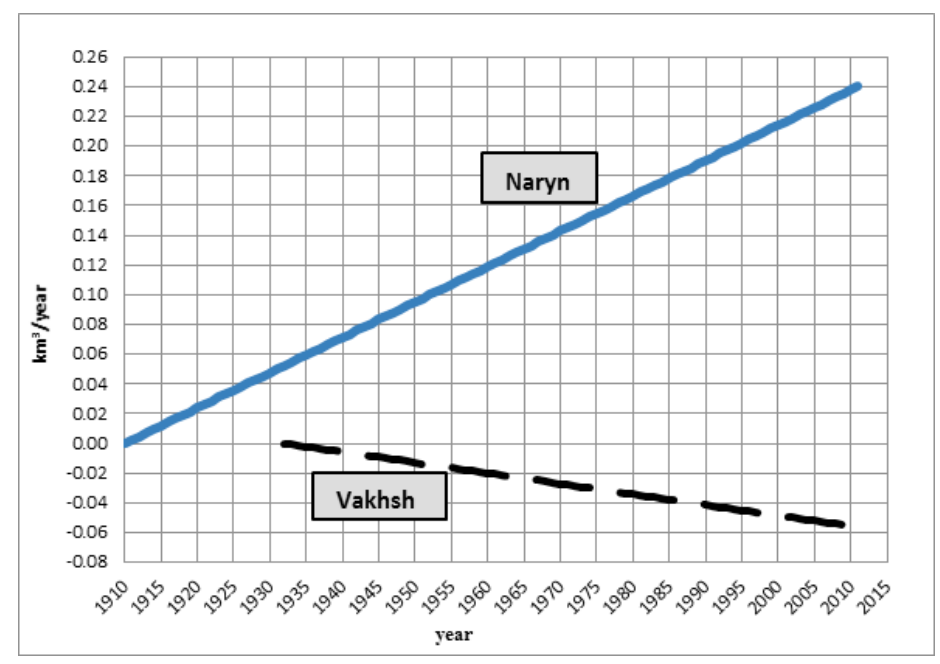

Figure 1: Normalized linear trends annual flow of the Vakhsh and Naryn rivers.

It is also difficult to find an explanation for the seemingly constant decrease in the water content of the r. Vakhsh, especially against the background of general trends of global climate change. All this shows the need for more detailed analysis.

In (Figures 2,3) show the results of calculations of the linear trends of the Vakhsh and Naryn rivers for individual periods. It can be seen that in this case the linear trend is not sustainable and reliable. For different periods, it varies in a very wide range, not only in absolute value, but even in sign. Therefore, using the general trend of long-term changes in water runoff to assess the impact of global climate change on it, as is often done, can be misleading. This suggests that some cyclical factors seem to influence the linear trend. In the present study, the GFFT, Mathcad [3] algorithm was used to identify the cyclic variability of the annual flow, which decomposes the actual data series into a Fourier series, that is, the sum of harmonics, each of which is a periodic oscillation with amplitude $\mathrm{A}_{\mathrm{k}}$ and initial phase $\varphi_{k}$ :

$y(t)=\sum_{k=0}^{n-1} A_{k} \cos \left(2 \pi k \frac{t}{T}-\varphi_{k}\right)$

where:

- $\mathbf{T}$ is the total length of the studied series of observations in years, the coefficients $\mathbf{A}_{\mathbf{k}}$ are the amplitudes of the kth harmonic, and $\varphi_{k}$ is its phase. The frequencies of all harmonics of the periodic function $y(t)$ are multiples of the fundamental frequency $F=1 / T$. Oscillation with a frequency $\mathrm{F}$ is called the first harmonic $(\mathrm{k}=1)$, with a frequency.

$2 \mathrm{~F}$ - the second harmonic $(\mathrm{k}=2)$, etc. $-\mathbf{t}$ is the current time.

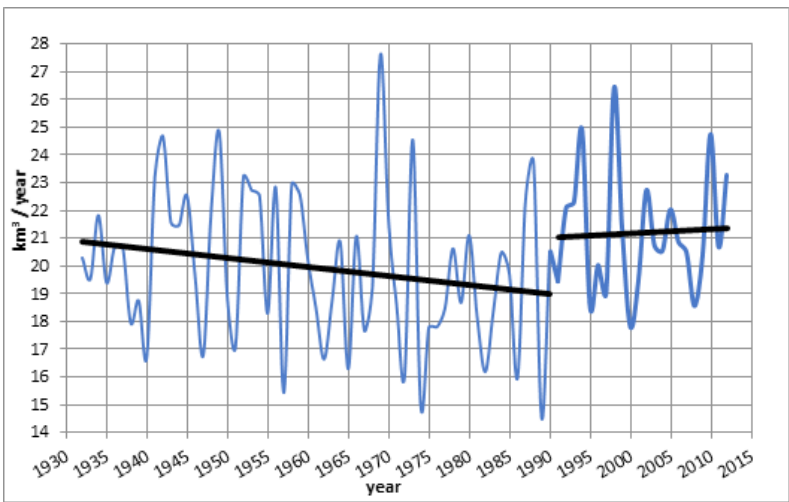

Figure 2: Linear trend of annual runoff $r$. Vakhsh.

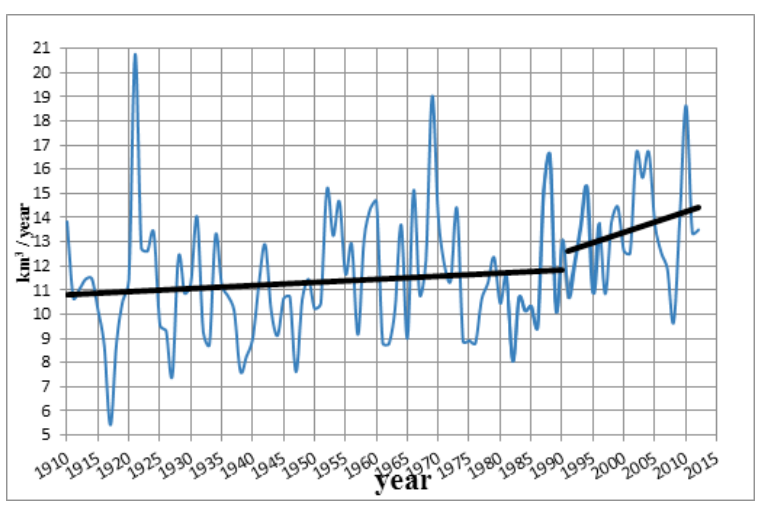

Figure 3: Linear trend of annual runoff r. Naryn.

The results of studies of cyclical fluctuations of the annual runoff of the Vakhsh and Naryn rivers are shown in (Figure 4). It is possible to note their certain synchronism, which, apparently, indicates that the same natural and climatic factors are the cause of cyclical fluctuations in the water content of these rivers.

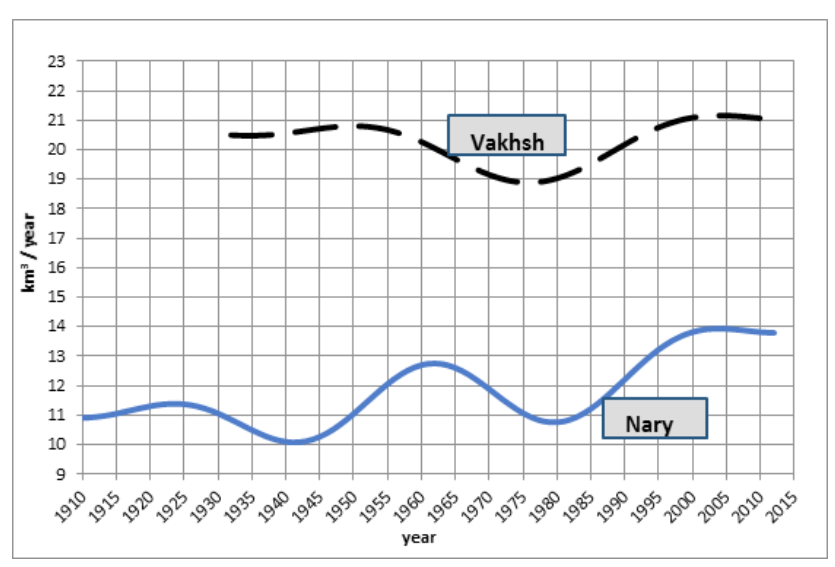

Figure 4: Cyclic fluctuations of the annual runoff of the Vakhsh and Naryn rivers. 


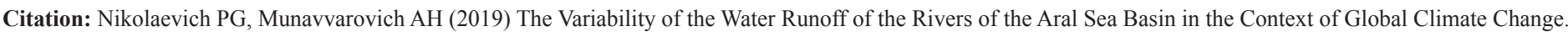
Curr Res Hydrol Res: CRHR-119. DOI: 10.29011/CRHR-119. 100019

Comparing (Figure 4) with (Figures 2,3), it can be seen that the linear trend of the annual flow of the Vakhsh and Naryn rivers is not constant in different periods because it actually describes different parts of cyclical variability. This is especially clearly seen in (Figure 5), where they are shown together. Therefore, a linear trend can be used to assess the general trend of changes in the water content of the studied rivers, only if the observations cover a sufficiently large number of cyclic variability periods, which is currently impossible, since the period of one cycle is about $40 \div 50$ or if it is calculated on the plots, the beginning and end of which coincide in phase.

Thus, in the presence of cyclical variability, linear trends are unrepresentative characteristics of time series and can lead to erroneous conclusions. This shows well the simplest example of a sine wave. On short segments - from $\pi / 2$ to $3 \pi / 2$, the linear trend will be sharply negative, on the segment $3 \pi / 2$ to $5 \pi / 2$ - sharply positive despite the fact that in reality the sinusoid should have a zero trend. On longer segments of the X-axis, if the phases of their beginning and end differ, the linear trend will also have a trend, only a weaker one. The above analysis of the time series of annual flows of the Vakhsh and Naryn rivers shows this picture (Figure 5).

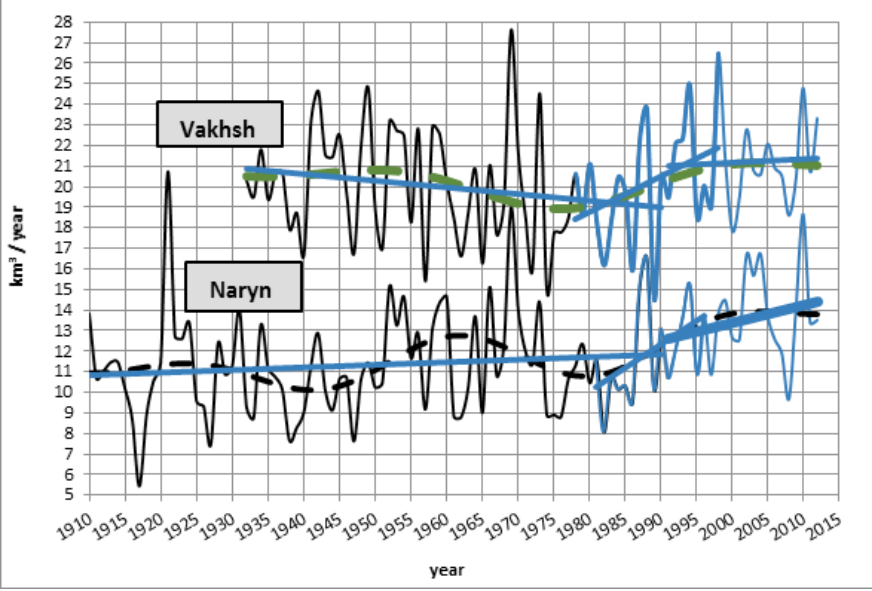

Figure 5: Trends and cyclical fluctuations of water content Naryn and Vakhsh rivers.

Representative linear trends of the Vakhsh and Naryn rivers, defined at time intervals, the beginning and end of which coincide in the phase of cyclic oscillations, are shown in (Figure 6). In this case, unlike (Figure 1) The linear trends of these two rivers are very close to each other and correlate well with the general trends of global climate change at the regional level. Thus, studies of cyclical fluctuations of water runoff are not only interesting in their own right, but also important for a representative assessment of linear trends and, consequently, a more reliable assessment of the impact of climate change on the region's water resources.

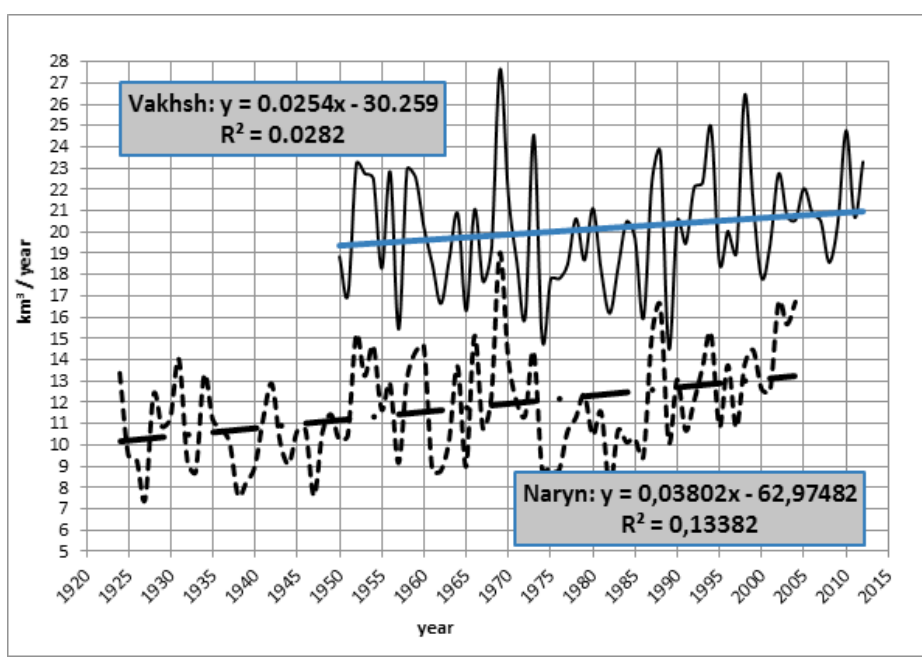

Figure 6: Linear trends of the annual flow of the Vakhsh and Naryn rivers (periods of observation with equal phases of beginning and end)

The performed studies indicate a rather high reliability of cyclic fluctuations of the water runoff of the Vakhsh and Naryn rivers, identified using the GFFT algorithm. But, unfortunately, this method cannot be used to predict cyclic variability, since when extending the considered period of time, the GFFT simply repeats the actually obtained calculation cycle.

This drawback can be overcome only in the method of direct expansion in a Fourier series, which is a multiple regression [4,5]:

$W_{t}=a_{0}+\sum_{n=1}^{n}\left(a_{n} \cos \mathrm{n} \pi \mathrm{T}_{n o r m}\right)+\sum_{n=1}^{n}\left(b_{n} \sin \mathrm{n} \pi \mathrm{T}_{n o r m}\right)$

where:

- $\mathbf{T}_{\text {norm }}$ - normalized year, calculated by the dependencies: $\mathrm{T}_{\text {norm }}=\left(\mathrm{t}_{\mathrm{i}}-\mathrm{t}_{0}\right) / \mathrm{T}_{\text {cycl }}$

- $\mathbf{t}_{\mathbf{0}}$ - the initial year of the cycle

- $\mathbf{T}_{\text {cycl }}$ - cycle period (the number of years of observations)

- $a_{0}, a_{n}, b_{n}$ - empirical expansion coefficients.

As experience has shown, to obtain stable results in formula (2), it is sufficient to take into account the first 4-5 members of the series (harmonics). For the forecast, it is necessary to extend $\mathrm{T}_{\text {cycl }}$ for the forecast period, $\mathrm{T}_{\text {norm}}$, with a corresponding change in the normalized year, $\mathrm{T}_{\text {norm }}$ :

$\mathrm{T}_{\text {cycl }}=\mathrm{T}_{\text {fact }}+\mathrm{T}_{\text {forecast }}$

$\mathrm{T}_{\text {norm }}=\left(\mathrm{t}_{\mathrm{i}}-\mathrm{t}_{0}\right) / \mathrm{T}_{\text {cycl }}=\left(\mathrm{t}_{\mathrm{i}}-\mathrm{t}_{0}\right) /\left(\mathrm{T}_{\text {fact }}+\mathrm{T}_{\text {forecast }}\right)$ 


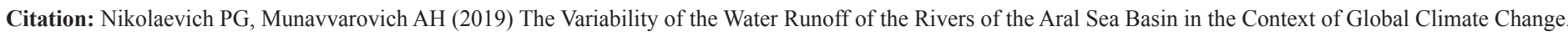
Curr Res Hydrol Res: CRHR-119. DOI: 10.29011/CRHR-119. 100019

Using the proposed approach in (Figure 7) shows the forecast of the water runoff of the Vakhsh and Naryn rivers until 2050.

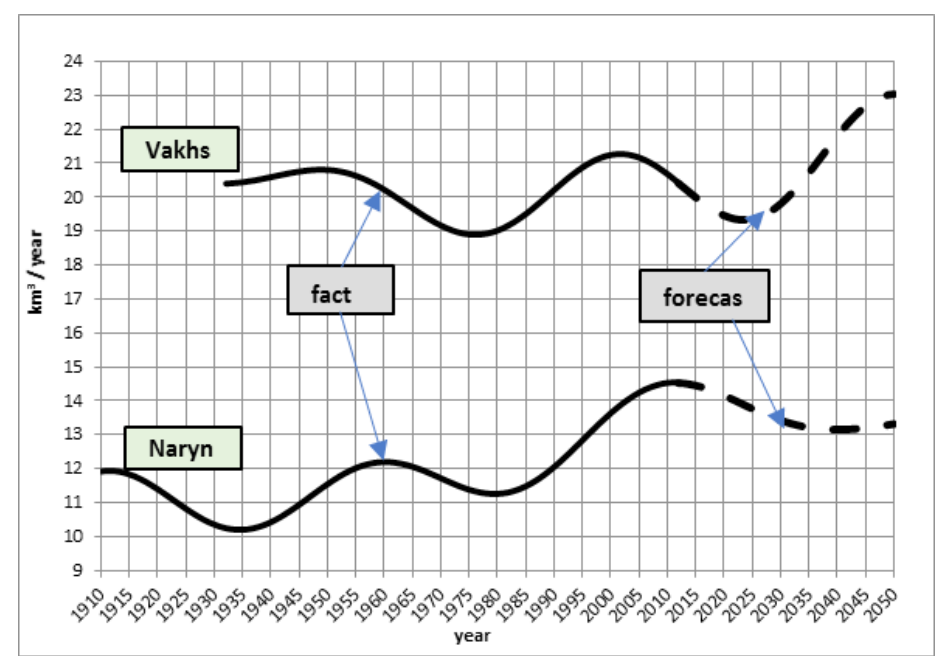

Figure 7: Forecast of water runoff of the Vakhsh and Naryn rivers.

For comparative analysis, (Table 1) shows the general parameters of the variability of the water flow of the Vakhsh river.

\begin{tabular}{|c|c|c|c|c|}
\hline $\begin{array}{c}\text { Type of } \\
\text { variation }\end{array}$ & Parameters & $\begin{array}{c}\mathbf{1 9 3 2} \\
\mathbf{2 0 1 2}\end{array}$ & $\begin{array}{c}\mathbf{1 9 3 2 -} \\
\mathbf{1 9 9 0}\end{array}$ & $\begin{array}{c}\mathbf{1 9 9 1 -} \\
\mathbf{2 0 1 2}\end{array}$ \\
\hline $\begin{array}{c}\text { Average } \\
\text { annual runoff }\end{array}$ & $\mathrm{km}^{3} / \mathrm{year}$ & 20.276 & 19.930 & 21.206 \\
\hline $\begin{array}{c}\text { Random } \\
\text { variations in } \\
\text { runoff }\end{array}$ & $\begin{array}{c}\text { Standard } \\
\text { deviation, } \\
\mathrm{km}^{3} / \mathrm{year}\end{array}$ & 2.350 & 2.385 & 2.298 \\
\hline $\begin{array}{c}\text { Linear trend } \\
\text { Linear trend } \\
\text { graent, } \mathrm{km}^{3} /\end{array}$ & +0.00641 & -0.03261 & +0.01548 \\
\hline $\begin{array}{c}\text { Cyclic } \\
\text { oscillations }\end{array}$ & $\begin{array}{c}\text { Amplitude, } \\
\mathrm{km}^{3} / \mathrm{year}\end{array}$ & \multicolumn{3}{|c|}{2.97 (14.63\% from the average } \\
long-term runoff)
\end{tabular}

Table 1: Parameters of variability of the water runoff of the Vakhsh river.

The presence of many years of cyclicality and random fluctuations of water runoff shows that the efficient use of water resources of rivers is possible only with the presence of reservoirs. An estimate of their total volume can be made on the basis of a general analysis of time series of water content. For this it is convenient to present the time series as a function:

$\sum\left(Q_{i}-\bar{Q}_{\text {average }}\right)=f\left(t_{i}\right)$

where:

$Q_{i}$ - the annual runoff for year i,
$\bar{Q}_{a}$ average - the average annual runoff for the entire observation period,

$\mathrm{t}_{\mathrm{i}}$ - time in years.

Calculations show that the optimal total volumes of these reservoirs should be equal to:

- for the Vakhsh River - $32.18 \mathrm{~km}^{3}$

- for the Naryn River - $32.5 \mathrm{~km}^{3}$

At the same time, today the total useful volume of reservoirs on the Naryn river is less than $15 \mathrm{~km} 3$, and in the Vakhsh river basin, the total useful volume of reservoirs is only $3.5 \mathrm{~km}^{3}$ and even after commissioning of the Rogun hydropower plant will be only $14 \mathrm{~km}^{3}$.

\section{Conclusions}

In the long run, global warming is the most stable factor in changing the water content of the rivers of the Aral Sea basin. Over the past hundred years, due to the constant melting of glaciers, which are the basis for feeding rivers in the region, their runoff has increased linearly by 0.0254 (Vakhsh river) $\div 0.0380$ (Naryn river) $\mathrm{km}^{3}$ per year. Apparently, such a tendency will continue for some time, after which, with the exhaustion of water supplies in the glaciers, the water content of the rivers in the region will begin to decrease. At the same time, the flow regime of the rivers will change.

In the medium term, cyclical fluctuations with a period of 40-60 years play the largest role in the variability of the rivers of the Aral Sea basin. Their amplitude significantly exceeds the linear trend associated with global warming. In the short term, the variability of the regional rivers' water content is determined by random fluctuations, the range of which is ten or more times the linear trend. Unfortunately, it is the random fluctuations of the river's water runoff that determine the current economic activity in the region, its current strategies and plans. This can lead to irreparable consequences in the long term.

\section{References}

1. (2004) Strengthening Cooperation for Rational and Efficient use of Water and Enercy resources in Central Asia. Special Programme for the Economies of Central Asia Project Working Group on Energy and Water Recouces. ECE/ESCAP 2004.

2. Petrov GN, Munavvarovich AH (2011) Complex use of water and energy resources of transboundary rivers of Central Asia. Current status, problems and solutions. LLC "Sapphire Company", Dushanbe 234.

3. Brent Maxfield (2006) Engineering with Mathad. Eisevier Ltd 365.

4. (1970) Fichtengolts GM Course of differential and integral calculus, volume III. "Science", Moscow 654.

5. Syngalevskaya GI (2005) Functions in Excel, Solution of practical problems. "Dialectics", Moscow, St. Petersburg, Kiev 880. 